\title{
Distilling Support Opportunities to Improve Urban Search and Rescue Missions
}

\author{
Tjerk de Greef ${ }^{1,2}$, A.H.J. Oomes ${ }^{1}$, and Mark A. Neerincx ${ }^{1,2}$ \\ ${ }^{1}$ Delft University of Technology, Man-Machine Interaction Group, Mekelweg 4, \\ 2628 GA Delft, the Netherlands \\ ${ }^{2}$ TNO Defence, Security and Safety, Department of Human Factors, Kampweg 5, 3769 ZG \\ Soesterberg, the Netherlands \\ t.e.degreefatudelft.nl, a.h.j.oomes@tudelft.nl, \\ mark.neerincx@tno.nl
}

\begin{abstract}
Current USAR missions are challenged by many factors leading to a study on how human computer interaction can provide support in this domain. Using data from a two-day observation in combination with mission reports, we applied a situated cognitive engineering design methodology to distill the operational demands, the human factors challenges, and the current and future technological design space. The operational demands result in a set of core functions that were explained in various parts of the USAR mission organization. Furthermore, an exemplary support scenario and prototype was provided in combination with claims on the envisioned effect.
\end{abstract}

Keywords: urban search and rescue, situated cognitive engineering, usercentered design, work domain analysis.

\section{Introduction}

Urban Search and Rescue (USAR) mission's goal is to excavate victims trapped in voids after a man made or natural disaster, such as an earthquake. Though teamwork and coordination are necessary for effective mission operation, the additional cognitive requirements may well result in a breakdown of the team structure. Furthermore, two additional aspects challenge teamwork in the USAR domain. First an USAR organization suffers from extreme difficult working conditions caused by the ambiguity of the situation and by the physical and emotional challenging circumstances despite the worker's excellent competencies, training, and motivation. Secondly, an USAR organization works at dispersed locations extending the cognitive requirements due to a temporal and/or spatial boundary between the team members.

In order to improve the effectiveness of USAR missions, we focus on human computer interaction support opportunities at problematic or critical elements in an USAR mission. We therefore applied a user centered design methodology coined situated cognitive engineering to establish support concepts and a requirements baseline. 


\subsection{Cognitive Engineering}

This study applied the situated cognitive engineering (sCE) methodology to establish a theoretically sound and empirically proven requirements database. The sCE methodology [1] was developed corresponding to the "classical" cognitive engineering methods [2-4] that consists of an iterative process of generation, evaluation, and refinement. In addition, the sCE method combined the classical human-centered perspective with a technology-centered perspective to systematically address the nature of both human and synthetic actors with their reciprocal dependencies as expressed in the joint cognitive systems paradigm. Furthermore, the sCE method includes an explicit transfer and refinement of general state-of-the-art theories and models - which include accepted features of human cognitive, affective, and social processes - into situated support concepts for the specific operational contexts [5].

Application of the sCE method results in a sound rule base (i.e., core functions, claims, and scenarios) with corresponding best practices for the application domain. The baseline possibly includes design patterns, software frameworks, and algorithms for core support functions.

The process of specification, refinement and validation is based on three information or feedback sources (see Fig 1). First a work domain and support analysis identifies operational, human factors, and technological challenges. Secondly an expert and task-analytical review assesses the rule base itself (i.e., scenarios, claims and core functions), and the third source describes scenario-based prototype evaluation of claims and core functions.

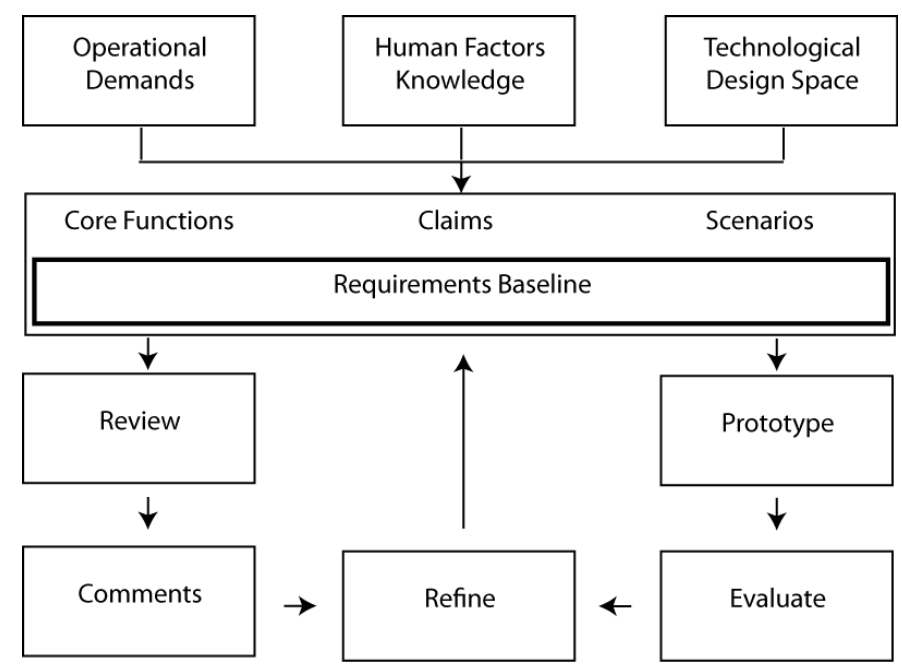

Fig. 1. The iterative process of requirements analysis (adapted from [1]) distills core functions, claims, and scenarios from operational demands, human factors knowledge, and a technological design space. These three aspects provide a requirements baseline that is evaluated using review and prototype evaluations. 
For the specification of the requirements baseline, we distinguish three steps that should be followed both from top and bottom. First, the core functions of the system are derived from the work domain and support analysis. Second, for each core function, one or more testable claims on its operational effects have to be specified; such a claim can be assessed unambiguously in review or evaluation processes. Both positive and negative claims can be specified. The claims consist of standard usability measures (i.e. effectiveness, efficiency, and satisfaction), and can easily be extended with other measures. Third, scenarios have to be specified describing coherent and situated stories about how an actor or team of actors will behave in specific circumstances with the operational consequences.

\section{Work Domain and Support Analysis}

\subsection{Operational Demands}

We conducted an operational analysis consisting of a cognitive work analysis (CWA) based on operational reports, lessons learned from previous missions, and a two-day observation at an USAR training facility. According to the ecological approach, a field description is fundamental to understand the domain in order to distill support concepts. CWA [6] is a work-centered conceptual framework designed to analyze cognitive work processes. A CWA recognizes five concepts to describe the domain and we will utilize these concepts to describe a typical USAR operation.

Work Domain. The system that an USAR organization or mission is controlling is the environment that is hit by a natural or a man made disaster, for example an earthquake. The work domain is characterized as an unstructured chaotic environment where possibly all critical social and governmental infrastructure facilities (e.g. power supplies, hospitals) have broken down and require a lot of effort to be operational. Depending on the size and type of the disaster, governmental problems of security and responsibility might arise.

A typical mission constructs a base camp that provides a resting facility and a command post. The actual search and rescue activities take place in so-called worksites.

Control Task. The goal of an urban search and rescue is to rescue trapped people after a natural or a man-made disaster. Besides rescuing trapped victims additional medical, reconstructive, and organizational tasks are executed by an USAR operation supportive to the additional goal in terms of flag planting. Every mission is politically determined based on considerations that often have limited correlation with humanitarian necessity. Furthermore, an USAR organization has to protect itself from inward and outward threats. Outward threats are defined by attacks or robberies on the organization while inward threat deals with the safety conditions of the organization itself (e.g., personal health, sanitation).

Strategies. An USAR organization has two general mechanisms to achieve their goals. First by putting the right action on the right place at the right moment provides the organization the largest chance to find survivors. Secondly, the safety of the own organization is guaranteed by integrating several information sources. 
Social Organization and Cooperation. An USAR mission recognizes a command group, a staff group, a support group, and a number of rescue groups (see Fig. 2). The command group is in charge of the operation while the staff and support groups have respectively delegated responsibilities and support functions for the overall management. Each search and rescue group consists of about eight to ten people of whom some have a specialized function like a group leader, a dog handler, a technical searcher, and a medic.

Furthermore, additional organizations are important. An USAR operation has to work in cooperation with the United Nation's Office for the Coordination of Humanitarian Affairs (OCHA), the home country's local operational team (LOT), and the local emergency management authority (LEMA). The OCHA organization is mandated to coordinate international assistance in disasters and humanitarian crises exceeding the capacity of the affected country. The LEMA has the ultimate authority for the overall command, coordination, and management of the response operation and can refer to national, regional, or local authorities (or combinations thereof) that are collectively responsible for the disaster response operation.

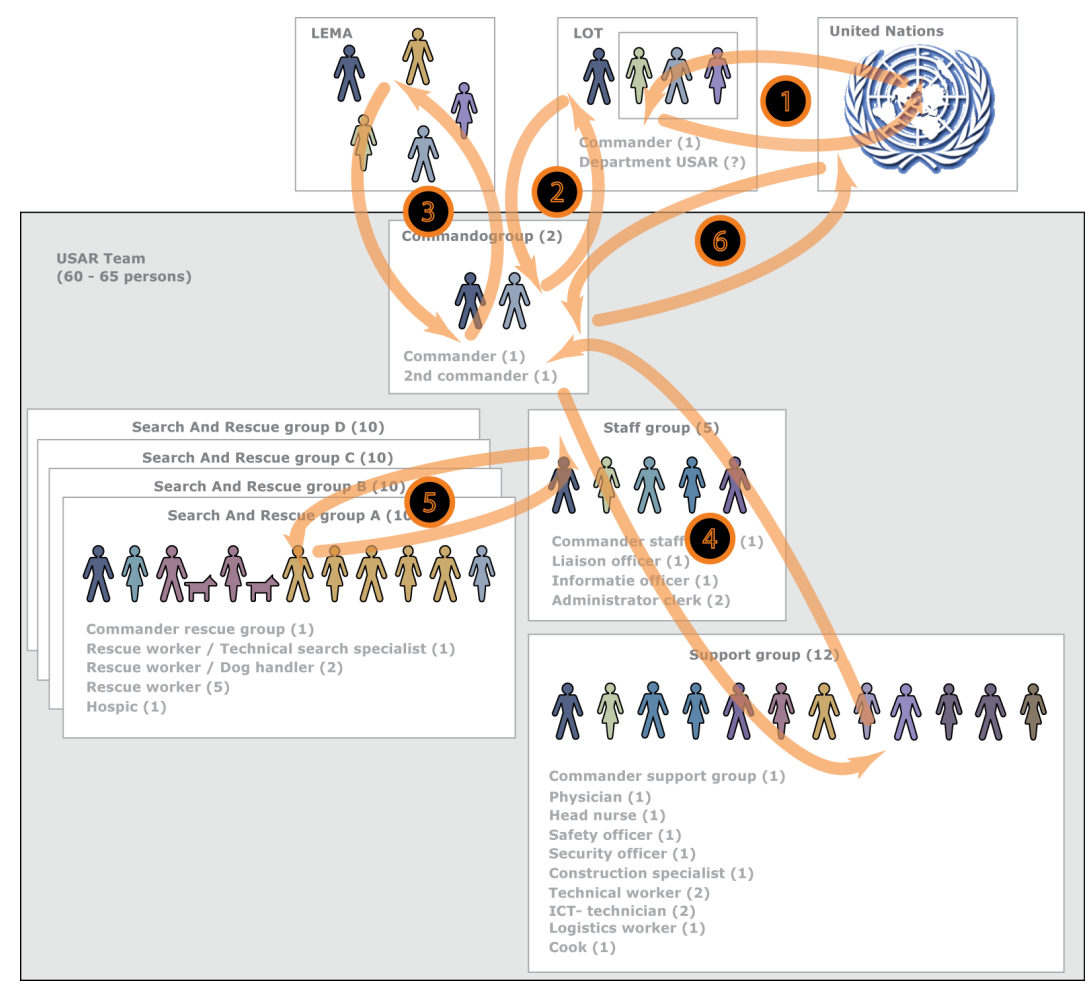

Fig. 2. A typical construction of an USAR mission deals with a United Nations office, a local emergency management authority (LEMA), a local operational team (LOT), a command group, a staff group, a support group, and four search and rescue groups. These groups coordinate joint activity using six coordination loops. 
In order to analyze the cooperation between the various groups we utilize the concept of coordination loops [7]. A coordination loop describes a process of coordination among actors where common ground is monitored and actions are mutually observed and (re)directed. A typical USAR mission acknowledges six coordination loops. The first loop (see Fig. 2) describes some sort of initialization loop. In order to have USAR teams respond, the troubled country needs to request assistance trough OCHA. OCHA will respond by asking available USAR teams to mobilize through each country's LOT. The second coordination loop describes the effort of the LOT to mobilize and transport an USAR team. Once an USAR team is available and present at the disaster site, coordination with the LEMA is required as the LEMA bears the ultimate authority (loop 3). The fourth loop reports a coordination effort between the command, staff, and support groups in order to optimize joint activity. The fifth and sixth coordination loop respectively describe an effort to maintain a common understanding between the search and rescue groups and the staff group and between the command group and the OCHA.

Worker Competencies. The USAR domain imposes some special requirements on the workers involved. Each member is required to have an excellent physical condition because the initial phase of a mission deprives each member of normal sleep. After this initial phase, a rotation system is put into place. In addition to these physical requirements, the workers must be emotionally fit as these emotions are challenged by the possible massive destruction caused by the disaster. To minimize post-traumatic stress experiences, post-mission debriefing sessions are mandated on a personal and a group level. The higher ranks of the USAR team require some diplomacy skills as goals of a LEMA might conflict with goals defined by either the UN or by the USAR team's government. A part of the team requires special technical skills to for example operate equipment or handle dogs.

\subsection{Human Factors}

In addition to the operations analysis, a review of human factors related issues in complex high demanding task environments resulted a number of key issues to be addressed by a support system.

First, situation awareness [8] and sense-making [9] relate respectively to the perception, comprehension, and projection of the elements in the environment and the process of making sense of the situation. Klein, Moon, and Hoffman [10] describe the latter as a motivated, continuous effort to understand connections (which can be among people, places, and events) in order to anticipate their trajectories and act effectively. The USAR domain is characterized by chaos in every detail: an unclear governmental structure, loss of all infrastructural connections, who has done what are typical chaotic examples within a typical mission.

Secondly, collaboration [11] refers to a coordinated attempt to obtain mutual benefits by sharing or partitioning work to achieve collective results that participants would be incapable of when working alone. The chaotic conditions after a disaster makes gaps and overlap in work a true risk for optimal joint activity and support helps to avoid these gaps and overlap in individuals' assigned work (i.e. support coordination). Furthermore, adding capability to support the generation and maintenance of a shared mental model for interdependent actors working at 
geographical different locations promises a useful capability. By mediating between actors, insight will be provided into the other actors' goals, intentions, behavior, and needs.

Third, crew resource management [12] is a combination of techniques used to train a crew to operate in complex environments, aiming to minimize the effects of errors related with human factors (including communication and cultural aspects) and to maximize effectiveness. A support system should manage the skills and task performance of the crew, and plan and support training to keep performance to a level required by operational demands.

Support for personal task load management such as emotion and physical task load come to surface as a forth opportunity. Each worker experiences physical demanding working conditions as set by the short mobilization period and continuous deployment. Besides these physical inconveniences, the environment is emotionally challenging as bizarre, unreal, and cruel sights dominate the mission potentially increasing the risk for post-traumatic stress experiences.

\subsection{Envisioned Technology}

In addition to the operations and human-factors analysis, we conducted a technology assessment that distinguished a number of developments that have potential to be applied in the USAR domain.

First, developments in sensing equipment technology show increasing capabilities to have technology available to have an inside view of collapsed structures helping rescue worker to improve assessing whether survivors are present. Secondly, a continuous push in the area of robotics lead to the application of unmanned (aerial) vehicles in the domain of USAR [13] enabling rescue workers a better visual overview with less related costs. These human robot interaction issues involve multiple people working with one robot while being in a different location. Third, various human computer interaction techniques, such as digital sketching pads and gesture recognition, show to have potential to be applied in the USAR field. Fourth, new sensor technology shows potential to be integrated in working outfits in order to sense, interpret, and anticipate individual human conditions and behaviors (e.g. to improve safety and health). Last, new developments in ad-hoc network technology facilitate means to be connected by one another in areas where limited connectivity exists.

\section{Requirements Baseline: First Iteration}

The previous section describes the first components of the sCE methodology. This section describes a first iteration of the construction of the requirements database thereby defining the core functions.

Based on the work domain and support analysis we distilled eight core functions (see Table 2 for explanation). Core functions are high-level tasks to be applied in a different part of the organization. 
Table 1. Core Functions within an urban search and rescue mission

\begin{tabular}{ll}
\hline Core Function & Explanation \\
\hline Manage Resources & $\begin{array}{l}\text { Relates to the organization of resources whether they be } \\
\text { personnel, equipment, or others like water supplies } \\
\text { This core function describes the current and future state of the } \\
\text { elements (and their relation) }\end{array}$ \\
Situation Assessment & $\begin{array}{l}\text { Despite the definition by [12] (crew resources management), this } \\
\text { core function relates to the location and physical and emotional } \\
\text { state of every living being (thus personnel and dogs) }\end{array}$ \\
Management & $\begin{array}{l}\text { Describes the activities required to have an optimal deployment } \\
\text { of the search \& rescue activities including all related } \\
\text { interdependent tasks }\end{array}$ \\
Planning Search \& & $\begin{array}{l}\text { Illustrates the undertaking to locate the victims by the utilization } \\
\text { of dogs, sensor equipment, and video footage } \\
\text { After locating a victim, the expertise required to rescue a victim } \\
\text { requires a so called attack route that describes the plan to rescue } \\
\text { a victim in relation to the victim's health, the fitness of the team, } \\
\text { and other pending tasks } \\
\text { Managing information to the media and family is sometimes a } \\
\text { Determine Attack }\end{array}$ \\
Route & $\begin{array}{l}\text { delicate matter while other information might flow to the LOT or } \\
\text { the OCHA }\end{array}$ \\
An important aspect is to have local knowledge \& contacts
\end{tabular}

Table 2. Breakdown of core functions subdivided by organizational part

\begin{tabular}{|c|c|c|}
\hline Local Organization & Search \& Rescue & $\begin{array}{l}\text { External } \\
\text { communication }\end{array}$ \\
\hline $\begin{array}{l}\text { Manage Resources } \\
\text { - } \quad \text { Personnel } \\
\text { - } \quad \text { Equipment } \\
\text { - } \quad \text { Resources } \\
\text { Situation Assessment } \\
\text { - } \quad \text { Environment } \\
\text { - } \quad \text { Base Camp } \\
\text { Human Resource management } \\
\text { - Check-In-Check-Out } \\
\text { - } \quad \text { Team Fitness } \\
\text { Planning Search \& Rescue }\end{array}$ & $\begin{array}{l}\text { Locate Victims } \\
\text { Manage Resources } \\
\text { - } \quad \text { Personnel } \\
\text { - } \quad \text { Equipment } \\
\text { - } \quad \text { Resources } \\
\text { Situation Assessment } \\
\text { - } \quad \text { Action areas } \\
\text { - } \quad \text { Buildings } \\
\text { - } \quad \text { Attack route management } \\
\text { - } \quad \text { Locals } \\
\text { Determine Attack Route } \\
\text { - } \quad \text { Medical Victim Assessment } \\
\text { - } \quad \text { Rescue/salvage } \\
\text { - } \quad \text { Team fitness } \\
\text { - } \quad \text { Communication with C.C. }\end{array}$ & $\begin{array}{l}\text { Manage } \\
\text { Information } \\
\text { - } \quad \text { Media } \\
\text { - } \quad \text { Family } \\
\text { - } \quad \text { Update LOT } \\
\text { centre } \\
\text { - Update } \\
\text { (v)OSSOC } \\
\text { Manage Contacts } \\
\text { - } \quad \text { LEMA } \\
\text { - } \quad \text { Local Embassy }\end{array}$ \\
\hline
\end{tabular}

In addition, we acknowledge three distinct organizational parts: local, search \& rescue, and external communication. The local organizational part refers to core functions required for the base camp to operate effectively and efficiently. The search $\&$ rescue organizational parts relate to the core functions that needs to be executed by every search and rescue team. A totally different aspect of the organization concerns 
Table 3. This scenario describes how the system supports the planning process leading to the claim that it improves effectiveness of the planning process and improves satisfaction of the search and rescue teams.

\begin{tabular}{|c|c|}
\hline Scenario & $\begin{array}{ll}\text { Effectiveness } & + \\
\text { Efficiency } & 0 \\
\text { Satisfaction } & + \\
\end{array}$ \\
\hline $\begin{array}{l}\text { Currently, search and rescue team } \\
\text { victims. Assessment of the attack } \\
\text { to rescue all victims leading to the } \\
\text { point in time, team Alpha makes } \\
\text { victims. The support system makes } \\
\text { group. The staff group has new i } \\
\text { chance to find survivors and they } \\
\text { instead of having them active at sit }\end{array}$ & $\begin{array}{l}\text { Alpha is deployed in worksite } 10 \text { and has located four } \\
\text { oute indicated a prolonged rescue operation at this site } \\
\text { plan to replace team Alpha by team Charlie. At some } \\
\text { huge progress reaching the goal of rescuing all four } \\
\text { the staff group aware of the rapid progress of the Alpha } \\
\text { fformation telling them that action area } 5 \text { has a high } \\
\text { reallocate team Charlie to be deployed at worksite } 5 \\
10 \text { where their presence is probably of limited use. }\end{array}$ \\
\hline
\end{tabular}

external communication that manages all official information flow to, for example, the media. Each core function is positioned in an organizational part and possible leading to different division of subtasks (see Table 3).

Second, for supporting a core function, one or more testable claims on its operational effects have to be specified. Such a claim can be assessed unambiguously in a review or a prototype evaluation. Both positive and negative claims can be specified. The claims all relate to effectiveness, efficiency, and satisfaction. Third, scenarios have to be specified. Scenarios are coherent and situated stories about how specific actors behave or will behave in specific circumstances.

\section{Prototype for Core Function Planning}

While the previous sections applied the sCE methodology on the USAR domain, this section provides a prototype that supports a core function in the local organization part of a mission: planning. First we provide an exemplary scenario including claims, and subsequently we clarify our support system using a prototype.

Table 3 reports a scenario offering support to the core function planning that materialized as results of observational data gathered during a two- day training mission. Currently, the planning staff has limited insight into the progress of task execution of search \& rescue groups leading to a diminished capability to observe deviations to the plan. Having such information aids the staff to identify significant deviations to the plan and enables them to update and improve the plan thereby maximizing effectiveness. The support therefore aims to offer support by making actions of (a team of) actors working at a different location observable thereby aiding a local actor in the observation, comprehension, and projection of the progress.

Fig. 3 displays an initial prototype offering insight into the progress towards goal accomplishment of team Alpha all in order to make predictions and anticipate deviations from the plan. Anticipation is the result of combining multiple dimensions. A navigation system, for example, anticipates the arrival time based on previous progress (e.g. 25 miles in 30 minutes) onto the remaining distance (e.g. 50 miles). This example shows that the temporal dimension and the distance dimension provide a two-dimensional space that is the basis for the anticipative act. 


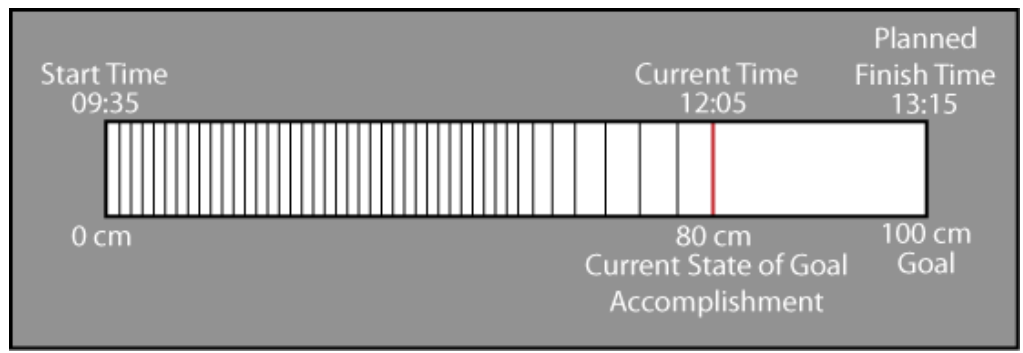

Fig. 3. A prototype display improves the insight of the progress of activities of a search \& rescue team

Anticipation in the USAR domain is based on a similar idea where progress on one dimension provides an indication on the progress on another dimension. Consider drilling activities of a search \& rescue team. Frequently these activities can last for hours and previous experience in combination with an estimate of the thickness and type of material provide a prediction in the temporal dimension.

Consider Fig. 3 where drilling through a structure is taken as an example. It is anticipated that the team requires 3 hours and 40 minutes of drilling to make a hole through one meter fortified concrete. The team starts at 9.35 leading to the prognoses that the drilling is finished at 13:15. At 12:05 the display indicates that the team has drilled through $80 \mathrm{~cm}$ and a simple calculation shows that they probably finish early as they have more than one hour left to drill through $20 \mathrm{~cm}$ of concrete while the previous $80 \mathrm{~cm}$ were covered in 2:30. The prototype fortifies the rapid progress prior to $12: 05$ by an increasing distance between lines indicating an increased drilled distance between fixed timestamps.

\section{Conclusion}

Current USAR missions are challenged by many factors leading to a study on how human computer interaction can provide support in this domain. We applied a situated cognitive engineering design methodology describing the operational demands, the human factors challenges, and the current and future technological design space leading to a scenario-based prototype. Future research will focus on the validation of these types of displays.

\section{Acknowledgements}

We gratefully acknowledge funding for our work from the IOP-MMI Programme that is run by SenterNovem, an agency of Dutch Ministry of Economic Affairs.

\section{References}

1. Neerincx, M.A., Lindenberg, J.: Situated Cognitive Engineering for complex task environments. In: Schraagen, J.M., Militello, J.M.C., Ormerod, L., Lipshitz, R. (eds.) Naturalistic Decision Making and Macrocognition, pp. 373-390. Ashgate Publishing Limited, Aldershot (2008) 
2. Hollnagel, E., Woods, D.D.: Cognitive systems engineering: New wine in new bottles. International Journal of Man-Machine Studies 18, 583-600 (1983)

3. Norman, D.A.: Cognitive Engineering. In: Norman, D.A., Draper, S.W. (eds.) UserCentered System Design: New perspectives on human-computer interaction, pp. 31-62. Lawrence Erlbaum Associates, Hillsdalte (1986)

4. Rasmussen, J.: Information Processing and Human-Machine Interaction: An Approach to Cognitive Engineering. North-Holland, Amsterdam (1986)

5. Neerincx, M.A.: Cognitive task load design: model, methods and examples. In: Hollnagel, E. (ed.) Handbook of Cognitive Task Design, pp. 283-305. Lawrence Erlbaum Associates, Mahwah (2003)

6. Vicente, K.J.: Cognitive Work Analysis. Lawrence Erlbaum Associates, Mahwah (1999)

7. Voshell, M.G., Woods, D.D., Prue, B., Fern, L.C.: Coordination Loops: a new unit of analysis for distrubuted work. In: Mosier, K., Fischer, U. (eds.) Proceedings of the Eighth International NDM Conference, Pacific Grove, CA (2007)

8. Endsley, M.: Design and evaluation for situation awareness enhancement. In: Proceedings of the Human Factor Society 32nd Annual Meeting, pp. 97-101. Human Factors Society, Santa Monica (1988)

9. Weick, K.E.: Sense-Making in organizations. Sage, Thousand Oaks (1995)

10. Klein, G., Moon, B., Hoffman, R.F.: Making sense of sensemaking I: alternative perspectives. IEEE Intelligent Systems 21, 70-73 (2006)

11. Mohammed, S., Dumville, B.C.: Team mental models in a team knowledge framework: Expanding theory and measurement across dsciplinary boundaries. Journal of Organizational Behaviour 22, 89-106 (2001)

12. Helmreich, R.L., Merritt, A.C., Wilhelm, J.A.: The evolution of Crew Resource Management training in commercial aviation. International Journal of Aviation Psychology 9, 19-32 (1999)

13. Murphy, R.R.: Human-Robot Interaction in Rescue Robotics. IEEE Transactions on Systems, Man, and Cybernetics - Part C: Applications and Reviews 34 (2004) 